\title{
MONETARY POLICY AND FINANCIAL CONDITIONS IN INDONESIA
}

\author{
Solikin M. Juhro', Bernard Njindan Iyke ${ }^{2}$ \\ ${ }^{1}$ Bank Indonesia Institute, Bank Indonesia, Jakarta, Indonesia. Email: solikin@bi.go.id \\ ${ }^{2}$ Centre for Financial Econometrics, Deakin Business School, Deakin University, \\ Melbourne, Australia. Email: bernard@deakin.edu.au
}

\begin{abstract}
We develop a financial condition index (FCI) and examine the effects of monetary policy on financial conditions in Indonesia. We show that our FCI tracks financial conditions quite well because it captures key financial events (the Asian financial crisis of 1997-1998, the Indonesian banking crisis, and the global financial crisis and its aftermath). A unique feature of our FCI is that it is quarterly and thus offers near real-time development in financial conditions. We also show that monetary policy shapes the FCI. A contractionary monetary policy leads to unfavourable financial conditions during the first two quarters, followed by favourable financial conditions for nearly three quarters. This finding is robust to an alternative identification strategy. Our findings highlight the critical role of the monetary authority in shaping financial conditions in Indonesia.
\end{abstract}

Keywords: Financial conditions; Monetary policy; Indonesia.

JEL Classifications: E44; E52.

Article history:

Received : September 15, 2018

Revised : January 2, 2019

Accepted : January 4, 2019

Available online : January 30, 2019

https://doi.org/10.21098/bemp.v21i3.1005 


\section{INTRODUCTION}

We create a new financial condition index (FCI) and analyse the effect of monetary policy on financial conditions in Indonesia. An FCI is a single indicator constructed to capture facets of the financial sector. Changing financial conditions are important for both policymakers and investors (Koop and Korobilis, 2014). Thus, a unique index to capture changing financial conditions has become popular in recent times. The debate on FCIs centres around what econometric approach and indicators of financial conditions should be used when constructing FCIs. For instance, Freedman (1994) contends that an FCI should capture exchange rate movements, whereas Dudley and Hatzius (2000) recommend the need for largescale macroeconomic indicators. In terms of approaches, two are mainly identified in the literature. The first, the so-called weighted-sum approach, involves assigning weights to the various indicators of financial conditions (DebuqueGonzales and Gochoco-Bautista, 2017). The weighting scheme derives from the relative impact on the real gross domestic product of each indicator, by simulating either structural or reduced-form macroeconomic models. The second approach is based on extracting common factors from a set of financial indicators using factor analysis or principal components analysis (Brave and Butters, 2011; Koop and Korobilis, 2014).

Among the earliest studies to construct FCIs are those of Goodhart and Hofmann (2001) and Mayes and Virén (2001), who note that house and stock prices are important drivers of financial conditions in the United Kingdom and Finland. Others, including Gauthier, Graham, and Liu (2004), Guichard and Turner (2008), and Swiston (2008), find corporate bond yield risk premiums and credit availability to be critical when constructing FCIs for Canada and the United States. FCIs have been extended to other economies, notably the Asian economies. Admittedly, the FCI literature in the Asian context is sparse. Studies such as those of Guichard, Haugh, and Turner (2009) and Shinkai and Kohsaka (2010) emphasize credit market conditions when constructing an FCI for Japan, while that of Osorio, Unsal, and Pongsaparn (2011) combine common factor and weighted-sum approaches when constructing FCIs for Asian economies. Debuque-Gonzales and Gochoco-Bautista (2017) have recently constructed FCIs for Asian economies using factor analysis.

We add to the limited studies on FCIs for Asian economies in the following ways. First, current studies construct FCIs using a panel of Asian countries (e.g. Osorio, Unsal, and Pongsaparn, 2011; Debuque-Gonzales and Gochoco-Bautista, 2017). Two issues arise under the panel setting: cross-sectional dependence and heterogeneities. Because these countries are interlinked via trade, analysing unique attributes of their FCIs becomes highly tasking within a single framework. Hence, there are merits to concentrating on a single country at a time. We overcome these issues by solely focusing on Indonesia. Empirically, Indonesia is quite appealing because of its financial and macroeconomic history. It was among the three countries most affected by the Asian Financial Crisis (AFC) of 1997-1998 (Goldstein, 1998; Yamazawa, 1998; Iyke, 2018a). ${ }^{3}$ The country also recently (i.e. on 3 September 2018) experienced the sharpest depreciation of its currency since

3 The other two are South Korea, and Thailand. 
the peak of the AFC (Iyke, 2018a). Agung, Juhro, and Harmanta (2016) argue that monetary policy alone is not sufficient to maintain macroeconomic stability and recommend complementary policies in Indonesia. In this regard, it is evident that understanding the evolution of the country's financial conditions will go a long way in helping policymakers pre-empt future deterioration and enhance stability.

Second, the impact of monetary policy on financial conditions in Indonesia and other Asian economies is poorly understood. Debuque-Gonzales and Gochoco-Bautista (2017) examine this issue but use annual data. Policymakers and investors alike are arguably more interested in the reactions of markets at higher frequencies to policy surprises as evidenced in their decisions. For instance, monetary policy decisions are carried out on a quarterly basis. Similarly, firms announce their financial reports quarterly. Thus, a great deal of information is lost when annual data are used. We circumvent this problem by employing quarterly data. In addition, we deal with the well-known price and exchange rate puzzles when identifying monetary policy shocks by including commodity prices and using an alternative recursive ordering of the variables in the model. ${ }^{4}$

The main goal of monetary policy is to achieve macroeconomic and price (or monetary) stability. As argued by Juhro and Goeltom (2013), macroeconomic and price stability are tied to financial system stability in Indonesia because they are interlinked. Therefore, since financial conditions generally shape the direction of the economy (i.e. they serve as a leading indicator of business activities), our FCI would be a useful tool to enhance the decisions of participants in the Indonesian economy. We find that our FCI tracks financial conditions quite well. For instance, it captures the peaks of the AFC and the Indonesian banking crisis, the relatively stable period from 2000 until 2008, and the global financial crisis and its aftermath. This is consistent with previous FCIs. A unique feature of our FCI is that it is quarterly and thus offers near real-time development in financial conditions. We also find that monetary policy shapes the FCI. A contractionary monetary policy leads to unfavourable financial conditions within the first two quarters. Financial conditions then improve for nearly three quarters, before declining. This finding is robust to an alternative identification strategy. Our findings highlight the critical role of the monetary authority in shaping financial conditions in Indonesia.

The remainder of the paper is organized as follows. Section II presents the model specification and the data. Section III discusses the results. Section IV concludes the paper.

\section{MODEL SPECIFICATION AND DATA}

\section{A. Model Specification}

This section outlines the approach used to construct the FCI. It also presents a Vector Autoregressive (VAR) model to examine the effect of monetary policy on financial conditions.

\footnotetext{
4 The price puzzle is a phenomenon whereby general prices react to a contractionary monetary policy shock by initially rising before falling (Sims, 1992). Christiano, Eichenbaum, and Evans (1999) recommend the inclusion of commodity prices to address this problem. The exchange rate puzzle arises when the exchange rate declines following a contractionary monetary policy shock (Cushman and Zha, 1997).
} 


\section{A1. Dynamic Factor Model to Construct the FCI}

We construct the FCI by employing a dynamic factor model. Given a set of endogenous variables (e.g. various indicators of economic and financial conditions), the dynamic factor model assumes that these variables are linear functions of certain unobserved factors and exogenous variables. The unobserved factors are therefore said to capture the movements of the set of endogenous variables. In theory, the unobserved factors and disturbances in the model are assumed to follow known correlation structures (Geweke, 1977; Stock and Watson, 1991). Following the literature (e.g. Geweke, 1977; Sargent and Sims, 1977), the following dynamic factor model can be specified:

$$
\begin{aligned}
& y_{t}=P f_{t}+Q x_{t}+u_{t} \\
& f_{t}=R w_{t}+A_{1} f_{t-1}+A_{2} f_{t-2}+\cdots+A_{t-p} f_{t-p}+v_{t} \\
& u_{t}=C_{1} u_{t-1}+C_{2} u_{t-2}+\cdots+C_{t-q} u_{t-q}+\epsilon_{t}
\end{aligned}
$$

where $y$ is a vector of dependent variables, $f$ is a vector of unobservable factors, $x$ and $w$ are vectors of exogenous variables, $u, v$, and $\epsilon$ are vectors of disturbances, $P, Q$, and $R$ are matrices of parameters, $A$ and $C$ are matrices of autocorrelation parameters, and $t, p$, and $q$ are time and lag subscripts, respectively.

In our application, $y$ contains the indicators of financial conditions (exchange rate, credit, interest rates, equity indices, and business conditions). These indicators are modelled as linear functions of unobserved factors assumed to follow a secondorder autoregressive process, to capture persistence in financial conditions. The FCI is the predicted vector of unobservable factors $\hat{f}$ (a one-step-ahead forecast of f). Following Stock and Watson (1991), we estimate the dynamic factor model by maximum likelihood. ${ }^{5}$

\section{A2. VAR Model for the Indonesian Economy}

We link monetary policy to financial conditions by estimating the following VAR model for the Indonesian economy:

$$
Y_{t}=\beta_{1} Y_{t-1}+\beta_{2} Y_{t-2}+\cdots+\beta_{q} Y_{t-q}+u_{t}
$$

where $Y_{t}$ is an $n \times 1$ vector of macroeconomic indicators (i.e. real output, consumer price index, FCI, commodity prices, Treasury bill rate, etc.), $\beta_{i}$ is an $n \times n$ parameter matrix, $u_{t}$ is the one-step-ahead independent and identically distributed forecast error with variance-covariance matrix $\Sigma, t$ and $q$ are time and lag subscripts, respectively.

5 In application, maximum likelihood is implemented in two steps. In the first step, the model is presented in state-space form. In the second step, the Kalman filter is used to derive and solve the log likelihood equation (Stock and Watson, 1991). 
The policy shock is identified through the one-step-ahead forecast error, $u_{t}$. Such a shock is structural and is transmitted to the entire economy. In practice, however, the decomposition of $u_{t}$ and an economically meaningful explanation of the structural shocks have remained a controversial topic. If we normalize $u_{t}$ into $v_{t}$ such that $E\left[v_{t} v_{t}^{\prime}\right]=I_{n^{\prime}}$ then there exists a matrix $A$ such that $u_{t}=A v_{t}$. The $j$ th column of $A$ denotes the instantaneous impact of the $j$ th fundamental innovation on all the variables. This fundamental innovation has one standard error in size (Uhlig, 2005; Iyke, 2018b). Therefore, $A$ is restricted by the variance-covariance matrix as follows:

$$
\Sigma=E\left[u_{t} u_{t}^{\prime}\right]=A E\left[v_{t} v_{t}^{\prime}\right] A^{\prime}=A A^{\prime}
$$

Equation (5) indicates $n(n-1) / 2$ degrees of freedom remaining in the model, which is not sufficient when identifying shocks to $u_{t}$. There are several approaches to address this problem. ${ }^{6}$ Consistent with Sims (1986), we do so by restricting $A$ to be a Cholesky factor of $\Sigma$. In other words, we use a recursive ordering of $Y_{t}$ when identifying shocks to $u_{t}$.

\section{B. Data}

Our sample covers the period 1994: Q1 to 2018: Q4. To construct the FCI, we use various variables indicating specific aspects of the financial conditions in Indonesia. We use Bank Indonesia's rate (IRATE) for the interest rate channel, the nominal effective exchange rate (NER) for the exchange rate channel, banking system claims on private enterprise (CREDIT) for the credit channel, the Jakarta Composite Index $(J C I)$ and the MSCI Share Price Index $(M S C I)$ for the equity channel, and the business confidence index $(B C I)$ and the consumer confidence index $(C C I)$ for the expectation or perception channel. In the VAR model, we use the manufacturing production index $(M P)$, the growth in $C P I$, the FCI, the commodity price index $(C O M), N E R$, the short-term interest rate or monetary policy rate (STR), and the monetary base or money supply (M2). The movements of these variables are shown in Figure A1 in the Appendix and the summary statistics and further details on the variables are presented in Tables A1 and A2, respectively.

\footnotetext{
6 See, for example, Bernanke (1986), Blanchard and Watson (1986), Blanchard and Quah (1989), Uhlig (2005), and Rubio-Ramírez, Waggoner, and Zha (2010). Each approach has its advantages and disadvantages.

7 Note that, since 2005 (under the inflation targeting framework), Bank Indonesia has used different policy rates. From 2005 until mid-2016, the bank used the Bank Indonesia Certificate (Sertifikat Bank Indonesia). Then, since mid-2016, the bank has used a seven-day reverse repo rate. These rates are slightly different (i.e. the former is around 150 basis points higher than the latter). This does not imply that Bank Indonesia has pursued an expansionary monetary policy, since the two rates have the same term structure. There has been no change in policy stance.
} 


\section{RESULTS}

\section{A. Measuring Financial Conditions}

We begin our analysis by testing for unit roots in the indicators of financial conditions. These results are shown in Table 1. There is no strong evidence to reject the unit root null hypothesis. Therefore, we proceed to constructing the FCI by modelling the indicators in their first differences as linear functions of an unobserved factor. The unobserved factor is assumed to follow a second-order autoregressive process.

Table 1.

\section{Tests for Unit Roots in FCI Constituents}

This table reports unit root test results based on the Augmented Dickey-Fuller (ADF) and the Perron and Vogelsang (PV, 1992) breakpoint tests. The null hypothesis is that there is a unit root. The breakpoint type is an innovation outlier. The break point is selected by minimizing the Dickey-Fuller statistic. A maximum of 12 lags is included in these models. Finally, ${ }^{* *}$ and ${ }^{* * *}$ denote, respectively, $5 \%$ and $1 \%$ significance levels.

\begin{tabular}{lcccc}
\hline \multirow{2}{*}{ Variable } & \multicolumn{2}{c}{ ADF test } & \multicolumn{2}{c}{ PV test } \\
\cline { 2 - 5 } & \multicolumn{2}{c}{ Zt-statistic (Lag) } & \multicolumn{2}{c}{ Innovation outlier } \\
\cline { 2 - 5 } & Constant & $\begin{array}{c}\text { Constant and } \\
\text { Trend }\end{array}$ & t-statistic (Lag) & \multirow{2}{*}{ Break date } \\
\hline IRATE & $-1.706(1)$ & $-2.324(1)$ & $-3.614(3)$ & $2008 \mathrm{M} 10$ \\
$\ln B C I$ & $-2.656(0)^{*}$ & $-4.316(0)^{* * *}$ & $-4.305(0)^{*}$ & $2009 \mathrm{M} 01$ \\
CCI & $-3.876(4)^{* * *}$ & $-4.469(4)^{* * *}$ & $-7.621(0)^{* * *}$ & $2002 \mathrm{M} 02$ \\
$\ln$ CREDIT & $-1.711(2)$ & $-0.997(2)$ & $-4.140(0)$ & $2000 \mathrm{M} 08$ \\
$\ln N E R$ & $-2.112(2)$ & $-2.510(1)$ & $-5.546(2)^{* * *}$ & $1997 \mathrm{M} 07$ \\
$\ln$ JCI & $-0.398(1)$ & $-2.660(1)$ & $-3.030(2)$ & $2003 \mathrm{M} 03$ \\
$\ln \mathrm{MSCI}$ & $-2.210(0)$ & $-1.734(0)$ & $-3.938(0)$ & $1998 \mathrm{M} 07$ \\
\hline
\end{tabular}

Table 2 shows the maximum likelihood estimates of the dynamic factor model. Because two of the constituents of the FCI, the business confidence index $(B C I)$ and the consumer confidence index $(C C I)$ have a short time span (i.e. they start in 2000:Q1, whereas the others start in 1994:Q1), we estimate the dynamic factor model with and without these variables. The seven variables used for the dynamic factor model are IRATE, NER, CREDIT, JCI, MSCI, BCI, and CCI. Model (1) contains all seven variables, whereas model (2) contains all seven except for $B C I$ and $C C I$. Both models generally indicate some degree of persistence in the unobserved factor, since immediate past values of the factor are significant in the model. The unobserved factor appears to be a significant predictor of all indicators except CREDIT in model (1). The factors have less predictive power over NER, CREDIT, and MSCI in model (2). The estimated signs of the coefficients are generally consistent with conventional wisdom; that is, we could infer that high interest rates tend to signal bad financial conditions, an appreciating rupiah exchange rate signals good financial conditions, high equity returns signal good financial conditions, and good business conditions (perceptions and expectations) translate to good financial conditions. 
Table 2.

\section{Dynamic Factor Estimates}

This table reports estimates of the dynamic factor model. The constituents of the FCI are specified in their first-differences as linear functions of an unobserved factor. The unobserved factor (i.e. the FCI) is assumed to follow a second-order autoregressive process. Models (1) and (2) contain, respectively, estimates with and without $\ln B C I$ and $C C I$. The full sample period is from 1994: Q1 to 2018: Q4. Finally, ${ }^{*}(* *) * * *$ denote statistical significance at the $10 \%(5 \%) 1 \%$ levels.

\begin{tabular}{lcc}
\hline Variables & \multicolumn{2}{c}{ Coefficient (z-statistic) } \\
\hline Factor & Model (1) & Model (2) \\
\hline Lag 1 & $0.432^{* * *}[3.650]$ & $0.507^{* *}[2.230]$ \\
Lag 2 & $-0.171[-1.440]$ & $-0.027[-0.260]$ \\
$\Delta I R A T E$ & $-0.238^{* * *}[-3.000]$ & $-0.063^{* * *}[-3.400]$ \\
$\Delta \ln N E R$ & $0.014^{* * *}[3.490]$ & $0.005[1.590]$ \\
$\Delta \ln C R E D I T$ & $0.010[0.290]$ & $-0.004[-0.310]$ \\
$\Delta \ln J C I$ & $0.108^{* * *}[11.750]$ & $0.018^{* * *}[4.740]$ \\
$\Delta \ln M S C I$ & $0.021^{*}[1.820]$ & $-0.002[-0.600]$ \\
$\Delta \ln B C I$ & $0.017^{* *}[2.090]$ & \\
$\Delta C C I$ & $1.964^{*}[1.820]$ & \\
& & 1503.705 \\
Log likelihood & -13.884 & 410.560 \\
Wald Chi-square $(8)$ & 152.100 & 0.000 \\
Prob $>$ Chi-square & 0.000 & 296 \\
Number of observations & 69 & $1994 \mathrm{Q} 1-2018 \mathrm{Q} 4$ \\
Sample & $2001 \mathrm{Q} 2-2018 \mathrm{Q} 4$ & \\
\hline
\end{tabular}

Figure 1 shows the extracted FCI values plotted against changes in interest rates and Figure 2 shows only the FCIs. ${ }^{8}$ The period between 1997 and 2002 was turbulent. Financial conditions worsened between 1997 and 1998, which were the peaks of the AFC and the Indonesian banking crisis (Iyke, 2018a). This time is followed by enhanced financial conditions between 1998 and 1999, a sharp decline between 1999 and 2001, and subsequent improvement between 2001 and 2002. Beyond this deterioration and recovery phase, financial conditions were moderate and stable in the country until a marked decline and subsequent recovery between 2008 and 2010. The fluctuations in our FCI look a bit similar to those of the annual FCI developed by Debuque-Gonzales and Gochoco-Bautista (2017). Of course, ours edges out theirs, in that it is quarterly and thus offers near real-time development in financial conditions. Policymakers and analysts alike are more concerned with developments in financial conditions at higher frequencies, as reflected in monetary policy announcements and quarterly financial reports. The next section therefore analyses how movements in our FCI are shaped by monetary policy.

8 The FCI with BCI and CCI appears to be smaller in absolute terms than the FCI without these two variables. The former captures the key FCI determinants and is therefore a more accurate indicator of financial conditions in the country than the latter. 


\section{Figure 1. FCI Movement}

This graph shows the movements of the FCI (with and without BCI and CCI) and interest rates (1994: Q1 to 2018: Q4).

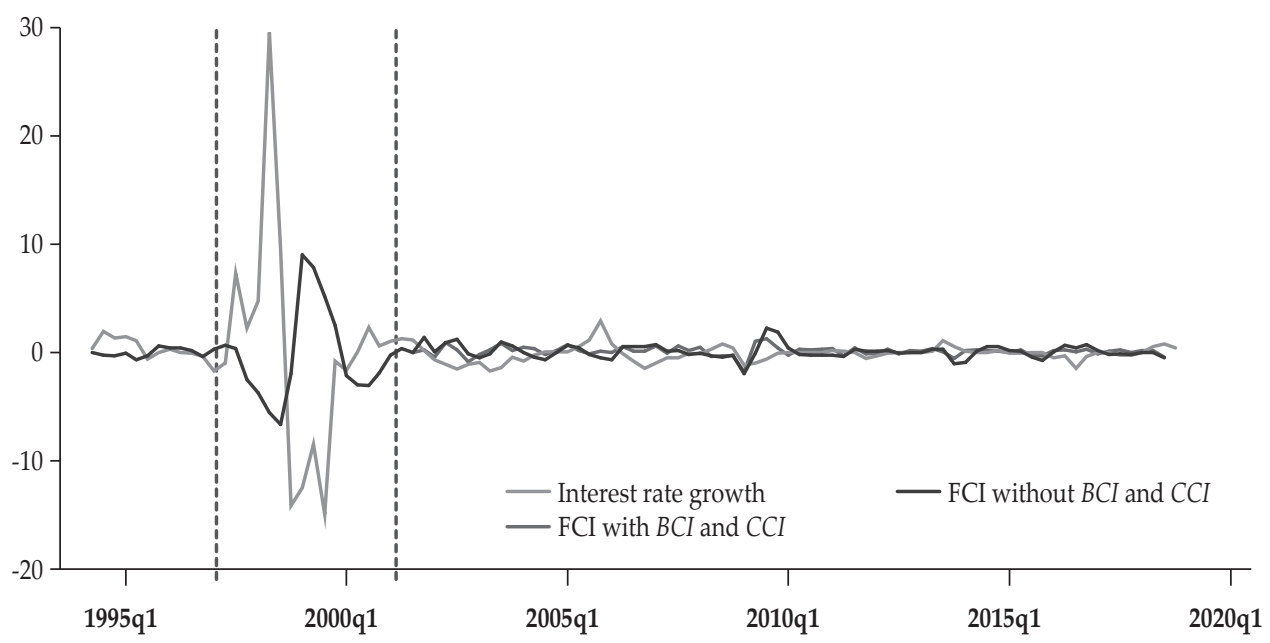

Figure 2. FCI for Indonesia

This graph shows the movements of the FCI for Indonesia (1994: Q1 to 2018: Q4).

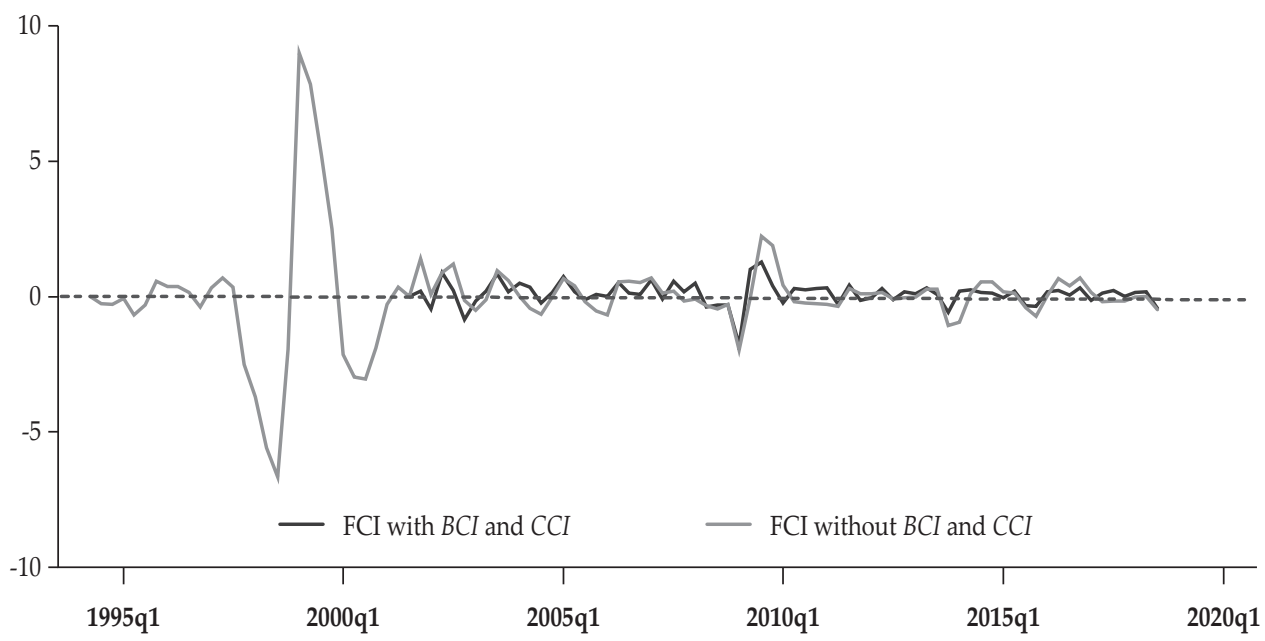

\section{B. Impact of Monetary Policy on Financial Conditions}

Financial conditions are not independent of monetary policies. The actions of monetary authorities tend to shape financial conditions. For instance, a tight monetary policy leads to credit shrinkage in the economy. This, in turn, leads to firms cutting down production, layoffs, declines in demand for goods and services, and reductions in business confidence. Similarly, an expansionary monetary policy leads to expansions in credit, production, employment, the demand for goods and services, and inflationary pressures, among others. Good financial conditions, if 
not properly safeguarded, can implode, owing to excessive speculative activities and lack of due diligence, especially in the area of credit allocation. The recent global financial crisis was mainly triggered by these factors.

In this section, we explore how financial conditions respond to monetary policy shocks (or surprises). In other words, we analyse how financial conditions respond to a sudden monetary policy contraction or expansion. We identify a monetary policy shock as an innovation in the short-term policy rate (STR). The monetary policy shock is based on a Cholesky decomposition of the variancecovariance matrix in equation (5), whereby STR is ordered last. We overcome the price and exchange rate puzzles by including the nominal exchange rate and commodity prices. The commodity prices are exogenous; therefore, $\ln C O M$ is ordered behind the monetary policy variable, STR. In terms of the degree of exogeneity of the remaining variables, we assume that $F C I$ is the most endogenous variable and we therefore order it first, followed by $\ln C P I$ (indicating demand push inflation pressures) and output $(\ln M P)$, in that order. Specifically, our benchmark identification equation is

$$
Y=[\ln F C I, \ln C P I, \ln M P, \ln N E R, \ln M 2, \ln C O M, S T R]
$$

In addition to imposing lower triangularity on $A$ in equation (5), we impose on $(B, \Sigma)$ a flat normal inverted-Wishart prior. ${ }^{9}$ We generate impulse response functions (IRFs) via 1,000 Markov chain Monte Carlo draws, a horizon of 10 quarters ahead, and two lags. ${ }^{10}$ The shock is one standard deviation in size. Thus, IRFs are bounded by the 16th and the 84th percentiles.

The resulting graph is shown in Figure 3. A contractionary monetary policy shock leads to unfavourable financial conditions (a decline in FCI below zero) one quarter after the shock. This deterioration in financial conditions persists until the end of the second quarter. Financial conditions improve (FCI rises above zero) for nearly three quarters before declining. We track the robustness of the FCI response to contractionary monetary policy by obtaining IRFs from an alternative ordering strategy. In this case, STR is ordered second but last. This identification is motivated by previous studies (e.g., Christiano, Eichenbaum, and Evans, 1999; Uhlig, 2005), which argue that monetary policy has an immediate effect only on the policy rate (short-term rate). Because monetary policy has a delayed effect on the economy (Christiano, Eichenbaum, and Evans, 1999), we order FCI first. Stated formally, our ordering strategy is

$$
Y=[\ln F C I, \ln M P, \ln C P I, \ln C O M, \ln N E R, \ln M 2, S T R]
$$

The graph for this strategy is shown in Figure 4. The IRF following a contractionary shock is qualitatively the same as that in Figure 3. Our findings are consistent with those of Satria and Juhro (2011), who document a strong impact of the monetary policy stance on financial sector policies. They document a consistent procyclical relationship between risk and credit-related variables and

\footnotetext{
9 Canova (2007) provides technical details on this prior restriction.

${ }^{10}$ We impose two lags because of considerations of sample size and degree of freedom.
} 
note that such a relationship tends to reverse the impact of expansionary monetary policy. We document that expansionary monetary policy is linked with favourable financial conditions for the first few quarters. In the medium term, our findings appear to corroborate theirs, in that financial conditions appear to decline, perhaps due to the reduction in risk-taking activities and credit facilities.

\section{Figure 3. Response of FCI to Monetary Policy Shocks}

This figure shows the response of financial conditions to a contractionary monetary policy shock of one standard deviation in size, which is identified as the innovation in the short-term interest rate, ordered last in Cholesky decomposition. The FCI is ordered first, followed by $\operatorname{lnCPI}$. The three lines denote the $16 \%$ quantile, the median and the $84 \%$ quantile of the posterior distribution.

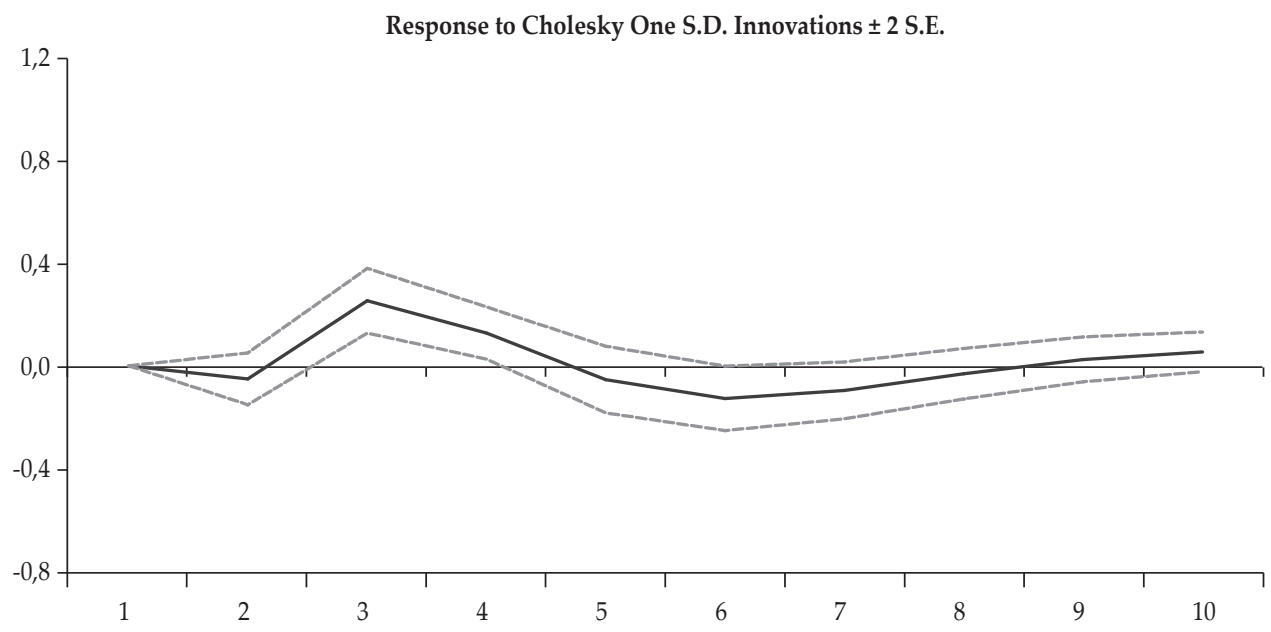

Figure 4. Response of FCI to Monetary Policy Shocks - Alternative Ordering

This figure shows the response of financial conditions to a contractionary monetary policy shock of one standard deviation in size, which is identified as the innovation in the short-term interest rate, ordered last in the Cholesky decomposition. The FCI is placed first, followed by $\ln M P$. The three lines denote the $16 \%$ quantile, the median and the $84 \%$ quantile of the posterior distribution.

Response to Cholesky One S.D. Innovations \pm 2 S.E.

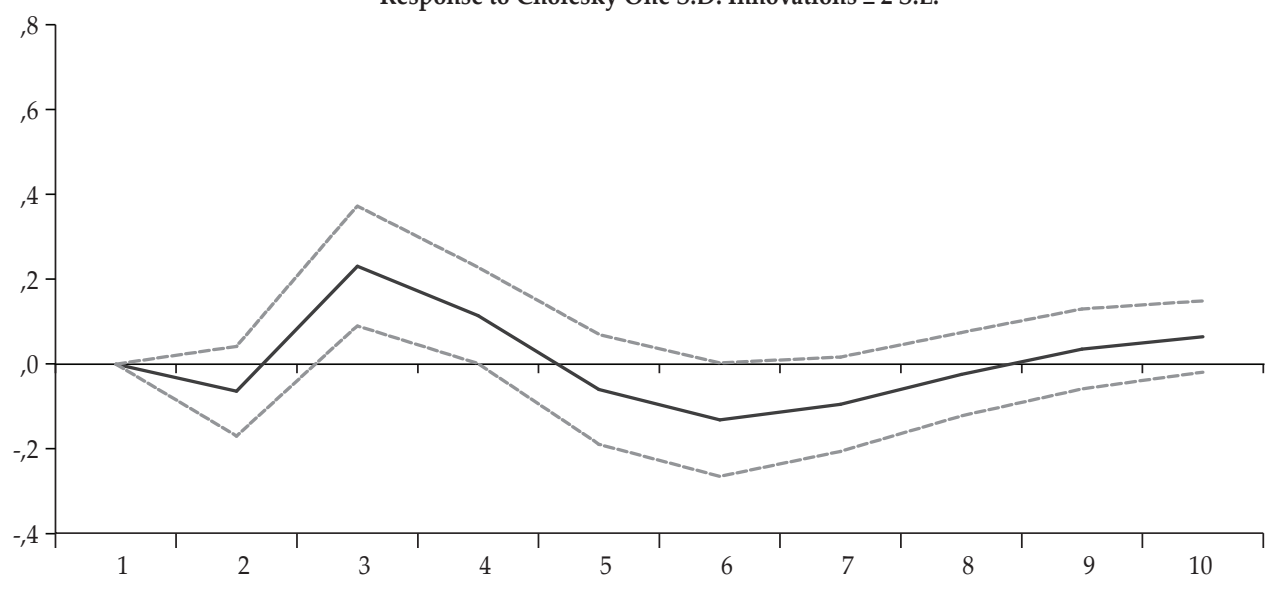




\section{CONCLUSION}

We create a new FCI and analyse the effect of monetary policy on financial conditions in Indonesia. There are, so far, only limited FCI studies on Asian economies. These studies are based on a panel of Asian economies; however, these countries are interlinked through trade and, therefore, analysis of the unique attributes of their FCIs becomes highly tasking within a single framework. We address this issue by solely focusing on Indonesia.

Indonesia has undergone substantial changes in terms of financial conditions, making it appealing for this study. The country is among the three that were most affected by the AFC. It has also, in recent times, experienced the sharpest depreciation in its currency since the peak of the AFC. Good FCIs would enhance authorities' abilities to pre-empt future deterioration in financial conditions. In addition, there is little understanding of the impact of monetary policy on financial conditions in Indonesia and other Asian economies. Previous attempts have used annual data, which might not be appealing, because policymakers and investors are arguably more interested in the reactions of markets to policy surprises at higher frequencies, as evidenced in their decisions. We address this point by employing quarterly data.

We find that our FCI tracks financial conditions quite well. For instance, it captures the peaks of the AFC and the Indonesian banking crisis, the relatively stable period from 2000 until 2008, and the global financial crisis and its aftermath. This is consistent with previous FCIs. A unique feature of our FCI is that it is quarterly and thus offers near real-time development in financial conditions. We also find that monetary policy shapes the FCI. A contractionary monetary policy leads to unfavourable financial conditions between the first and second quarters. Financial conditions then improve for nearly three quarters, before declining. This finding is robust to an alternative identification strategy. Our findings highlight the critical role of the monetary authority in shaping financial conditions in Indonesia. In this case, a significant countercyclical monetary policy impact on financial conditions opens up room to augment the standard monetary policy rule by incorporating an unexpected development (deviation) of financial conditions.

\section{REFERENCES}

Agung, J., Juhro, S. M., \& Harmanta, T. (2016) Managing Monetary and Financial Stability in a Dynamic Global Environment: Bank Indonesia's Policy Perspectives (October 2016). BIS Paper No. 88f. Available at SSRN: https://ssrn. com/abstract $=2861312$.

Bernanke, B. S. (1986). Alternative Explanations of the Money-Income Correlation. In: Brunner, K., \& Meltzer, A. (Eds.), Real Business Cycles, Real Exchange Rates, and Actual Policies. Carnegie-Rochester Conference Series on Public Policy, vol. 25. North-Holland, Amsterdam.

Blanchard, O., \& Watson, M. (1986). Are All Business Cycles Alike? In: Gordon, R.J. (Ed.), The American Business Cycle. University of Chicago Press, Chicago, 123-160.

Blanchard, O. J., \& Quah, D. (1989). The Dynamic Effects of Aggregate Demand and Supply Shocks. American Economic Review, 79, 655-673. 
Brave, S., \& Butters, R. (2011). Monitoring Financial Stability: A Financial Conditions Index Approach. Economic Perspectives, 35, 22-43.

Canova, F. (2007). Methods for Applied Macroeconomic Research. Princeton, NJ: Princeton University Press.

Christiano, L., Eichenbaum, M., \& Evans, C. (1999). Monetary Policy Shocks: What Have I Learned and to What End? In: Woodford, M., Taylor, J.B. (Eds.), Handbook of Macroeconomics. North-Holland, Amsterdam, 65-148.

Cushman, D. O., \& Zha, T. (1997). Identifying Monetary Policy in a Small Open Economy Under Flexible Exchange Rates. Journal of Monetary Economics, 39, 433-448.

Debuque-Gonzales, M., \& Gochoco-Bautista, M. S. (2017). Financial Conditions Indexes and Monetary Policy in Asia. Asian Economic Papers, 16, 83-117.

Dudley, W., \& Hatzius, J. (2000). The Goldman Sachs Financial Conditions Index: The Right Tool for a New Monetary Policy Regime. Global Economics Paper No. 44.

Freedman, C. (1994). The Use of Indicators and of the Monetary Conditions Index in Canada. Frameworks for monetary stability: policy issues and country experiences, 458-476.

Gauthier, C., Graham, C., \& Liu, Y. (2004). Financial Conditions Indexes for Canada. Bank of Canada Working Paper No. 2004-22.

Geweke, J. (1977). The Dynamic Factor Analysis of Economic Time Series Models. In Latent Variables in Socioeconomic Models, ed. D. J. Aigner \& A. S. Goldberger, 365-383. Amsterdam: North-Holland.

Goldstein, M. (1998). The Asian Financial Crisis: Causes, Cures, and Systemic Implications. Peterson Institute, 55.

Goodhart, C., \& Hofmann, B. (2001). Asset Prices, Financial Conditions, and The Transmission of Monetary Policy. In conference on Asset Prices, Exchange Rates, and Monetary Policy (March, 2001), Stanford University (2-3).

Guichard, S., \& Turner, D. (2008). Quantifying the Effect of Financial Conditions on US Activity. OECD Economics Department Working Paper No. 635.

Guichard, S., Haugh, D., \& Turner, D. (2009). Quantifying the Effect of Financial Conditions in the Euro Area, Japan, United Kingdom, and United States. OECD Economics Department Working Paper No. 677.

Iyke, B.N. (2018a) A Test of the Foreign Exchange Market Efficiency in Indonesia. Bulletin of Monetary Economics and Banking (forthcoming).

Iyke, B. N. (2018b). Assessing the Effects of Housing Market Shocks on Output: The Case of South Africa. Studies in Economics and Finance, 35, 287-306.

Juhro, S. M., \& Goeltom, M. (2013) The Monetary Policy Regime in Indonesia (November 1, 2013). Macro-Financial Linkages in Pacific Region, Akira Kohsaka (Ed.), Routledge, February 2015. Available at SSRN: https://ssrn.com/ abstract $=2875631$.

Koop, G., \& Korobilis, D. (2014). A New Index of Financial Conditions. European Economic Review, 71, 101-116.

Mayes, D., \& Virén, M. (2001). Financial Conditions Indexes. Bank of Finland Discussion Paper No. 2001-17. 
Rubio-Ramírez, J., Waggoner, D., \&Zha, T. (2010). Structural Vector Autoregressions: Theory of Identification and Algorithms for Inference. Review of Economic Studies, 77, 665-696.

Satria, D., \& Juhro, S. M. (2011). Risk Behavior in the Transmission Mechanism of Monetary Policy in Indonesia. Bulletin of Monetary Economics and Banking, 13, 243-270.

Sargent, T. J., \& Sims,C. A. (1977). Business Cycle Modeling without Pretending to Have too much a Priori Economic Theory. In New Methods in Business Cycle Research: Proceedings from a Conference, ed. C. A. Sims, 45-109. Minneapolis: Federal Reserve Bank of Minneapolis.

Shinkai, J.-I., \& Kohsaka, A. (2010). Financial Linkages and Business Cycles of Japan: An Analysis Using Financial Conditions Index. OSIPP Discussion Paper No. 2010-E-008. Osaka School of International Public Policy.

Sims, C. A. (1986). Are Forecasting Models Usable for Policy Analysis. Minneapolis Federal Reserve Bank Quarterly Review Winter, 2-16.

Sims, C. A. (1992). Interpreting the Macroeconomic Time Series Facts. European Economic Review, 36, 975-1011.

Stock, J. H., \& Watson, M. W. (1991). A Probability Model of the Coincident Economic Indicators. In Leading Economic Indicators: New Approaches and Forecasting Records, ed. K. Lahiri and G. H. Moore, 63-89. Cambridge: Cambridge University Press.

Swiston, A. (2008). A U.S. Financial Conditions Index: Putting Credit where Credit is Due. IMF Working Paper No. 08/161.

Osorio, M. C., Unsal, D. F., \& Pongsaparn, M. R. (2011). A Quantitative Assessment of Financial Conditions in Asia (No. 11-170). International Monetary Fund.

Perron, P., \& Vogelsang, T. J. (1992). Nonstationarity and Level Shifts with an Application to Purchasing Power Parity. Journal of Business E Economic Statistics, 10, 301-320.

Uhlig, H. (2005). What are the Effects of Monetary Policy on Output? Results from an Agnostic Identification Procedure. Journal of Monetary Economics, 52, 381419.

Yamazawa, I. (1998). The Asian Economic Crisis and Japan. The Developing Economies, 36, 332-351. 


\section{APPENDIX}

\section{Figure A1. Variables Used for Constructing FCI and the VAR Model}

This figure shows the behaviour of the variables used in constructing the FCI and the VAR model. The first seven graphs are the financial condition indicators used in the FCI model. The last seven (including lnNER) graphs are those variables used in the VAR model to examine the impact of monetary policy shocks on financial conditions. The maximum sample period employed is from 1994: Q1 to 2018: Q4.
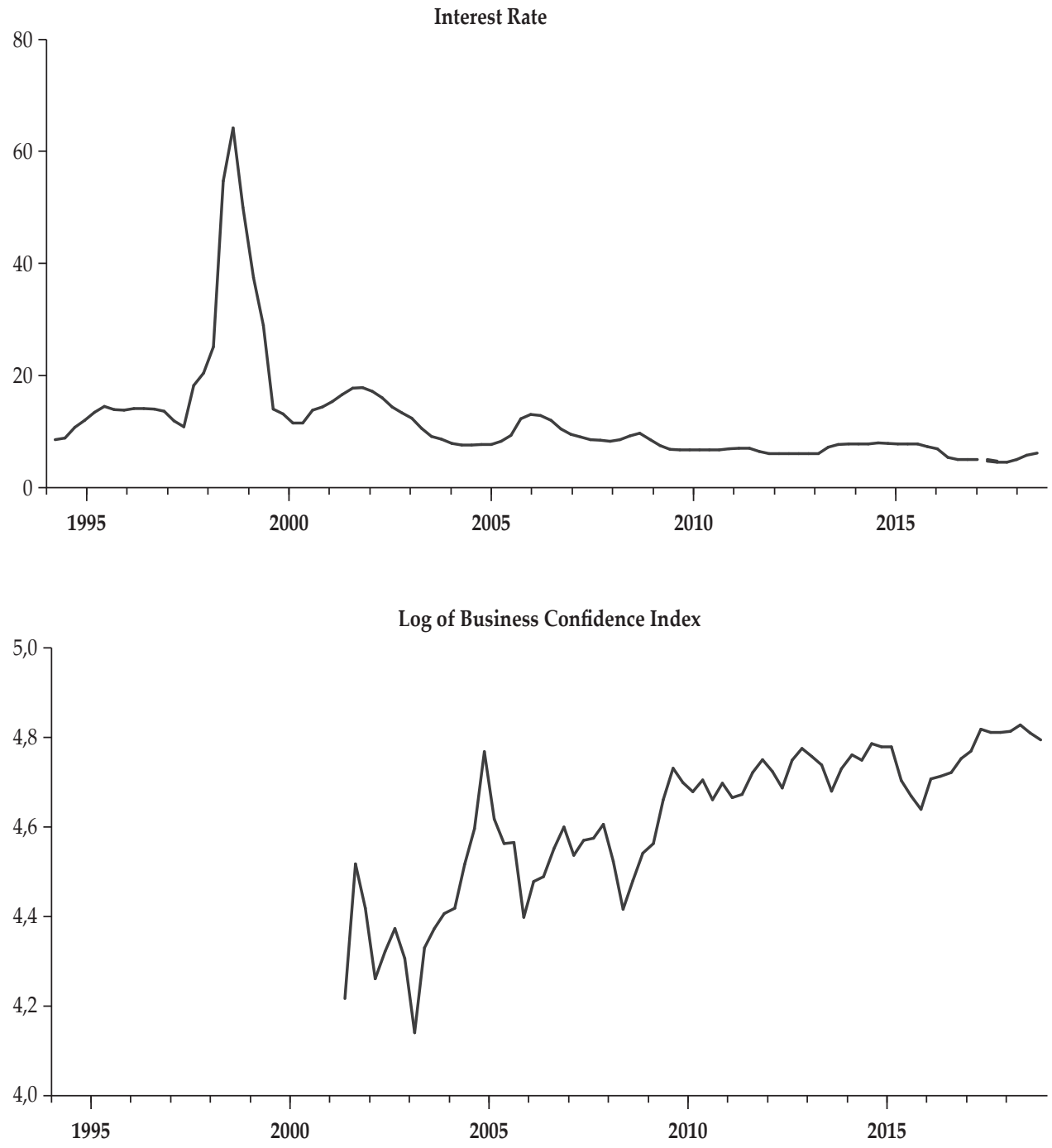
Figure A1. Variables Used for Constructing FCI and the VAR Model (Continued)
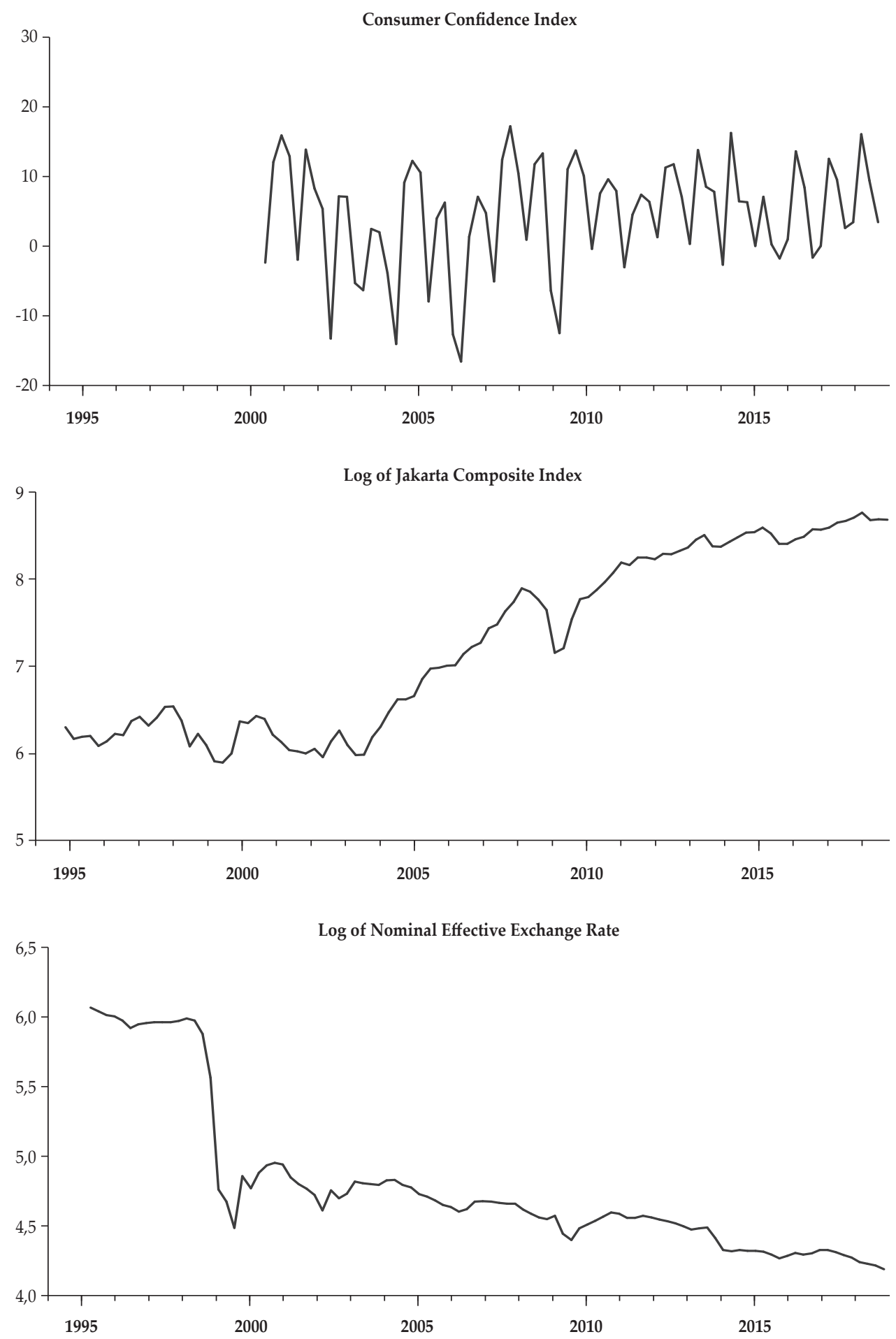
Figure A1. Variables Used for Constructing FCI and the VAR Model (Continued)
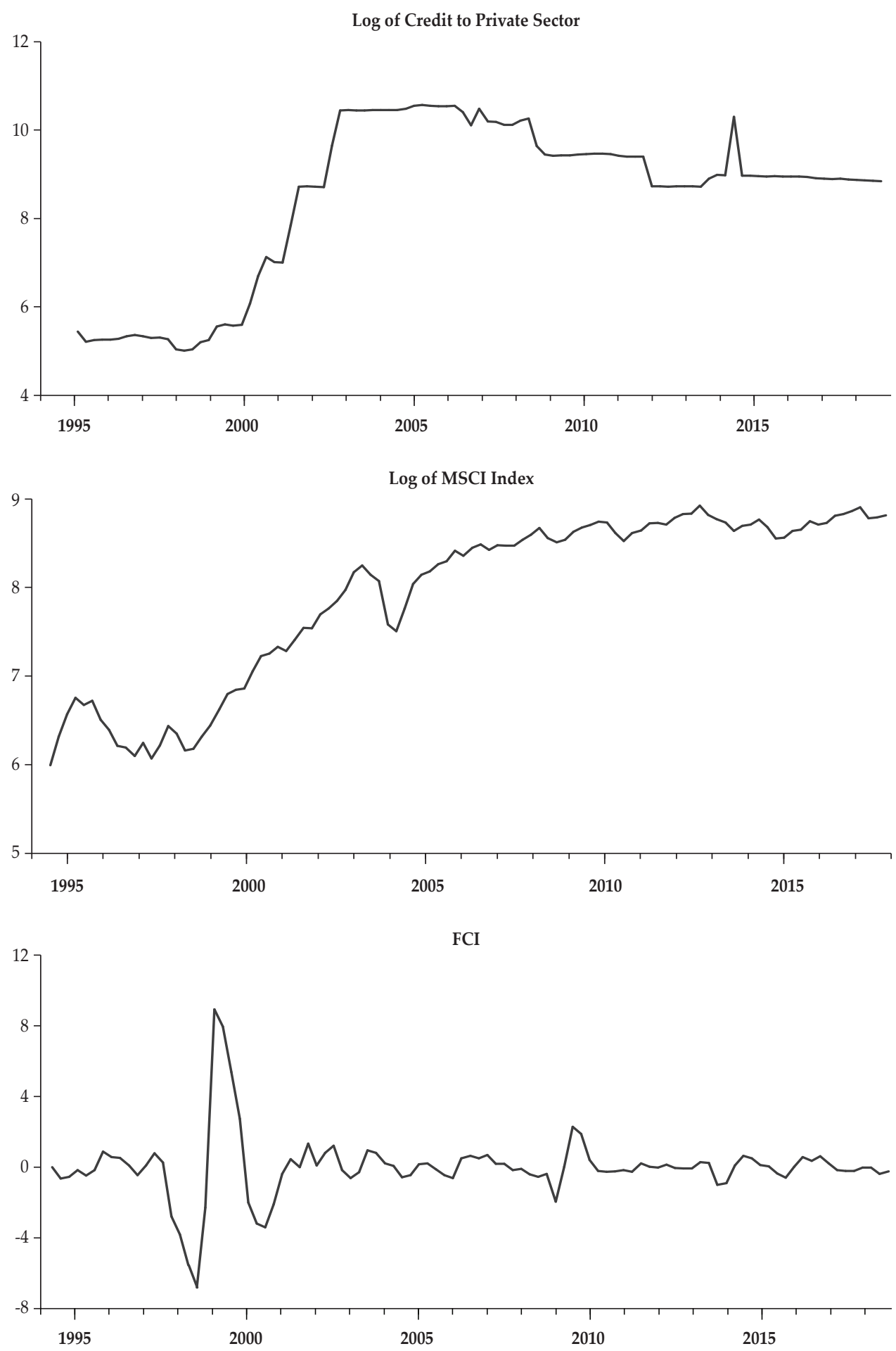
Figure A1. Variables Used for Constructing FCI and the VAR Model (Continued)
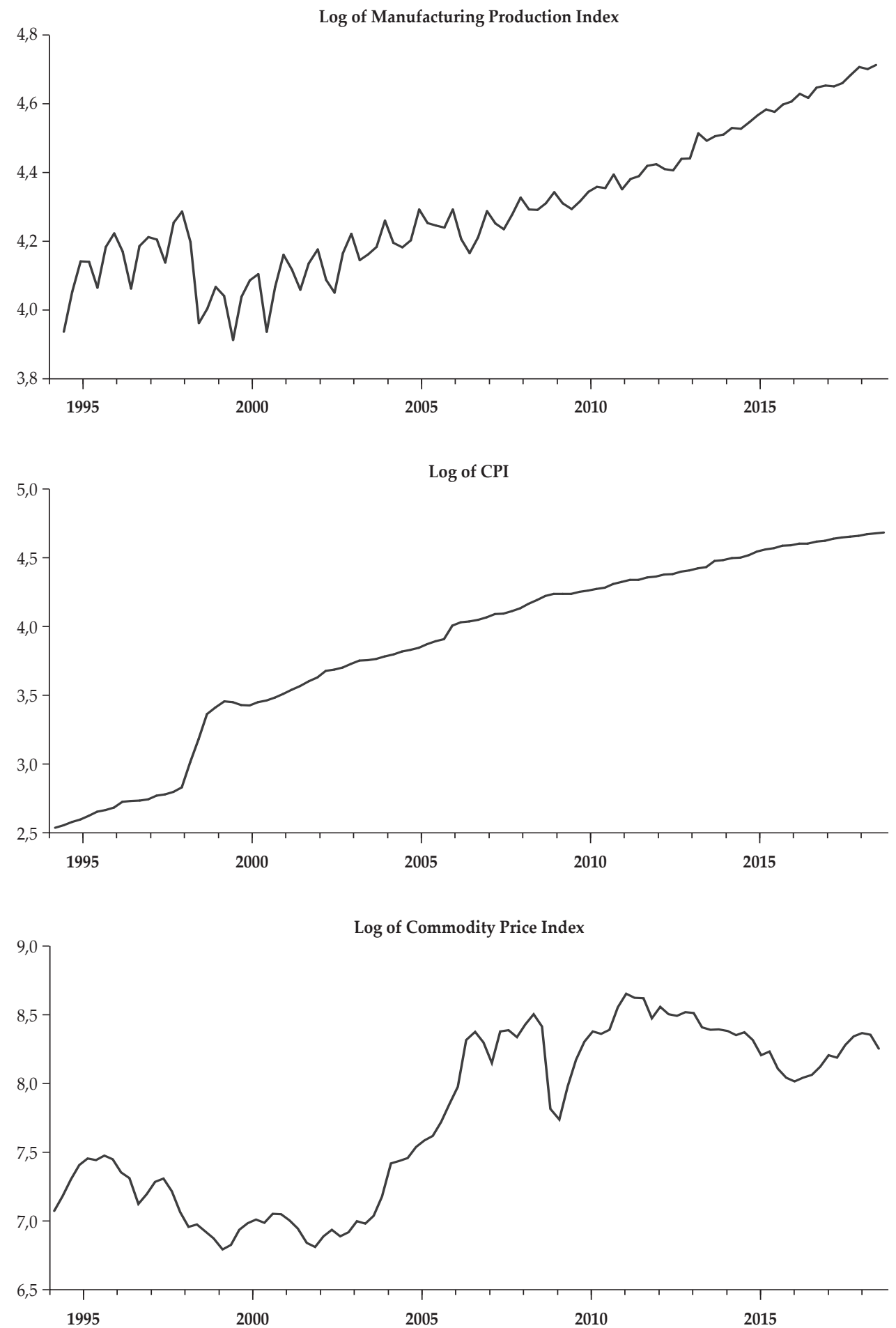
Figure A1. Variables Used for Constructing FCI and the VAR Model (Continued)
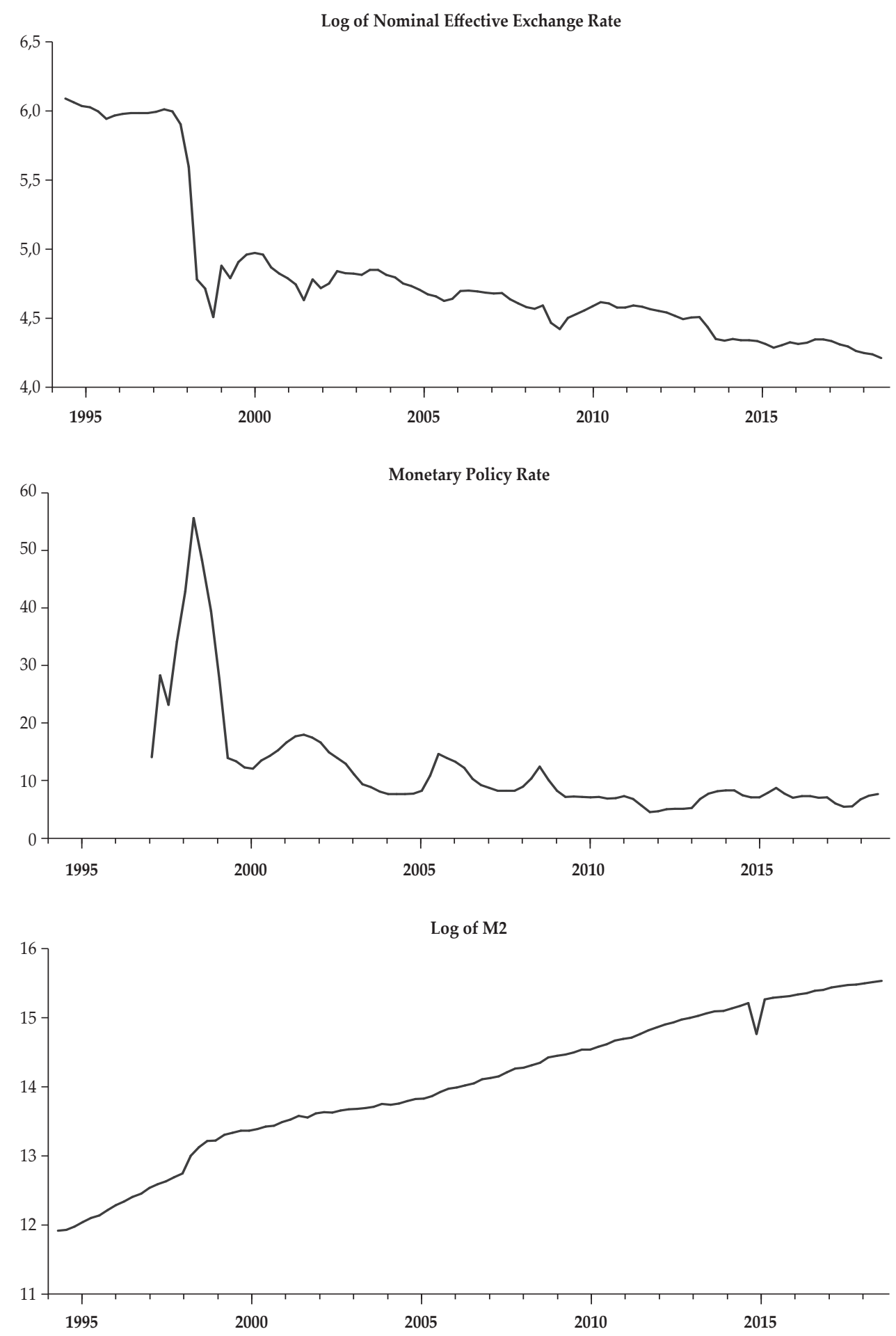


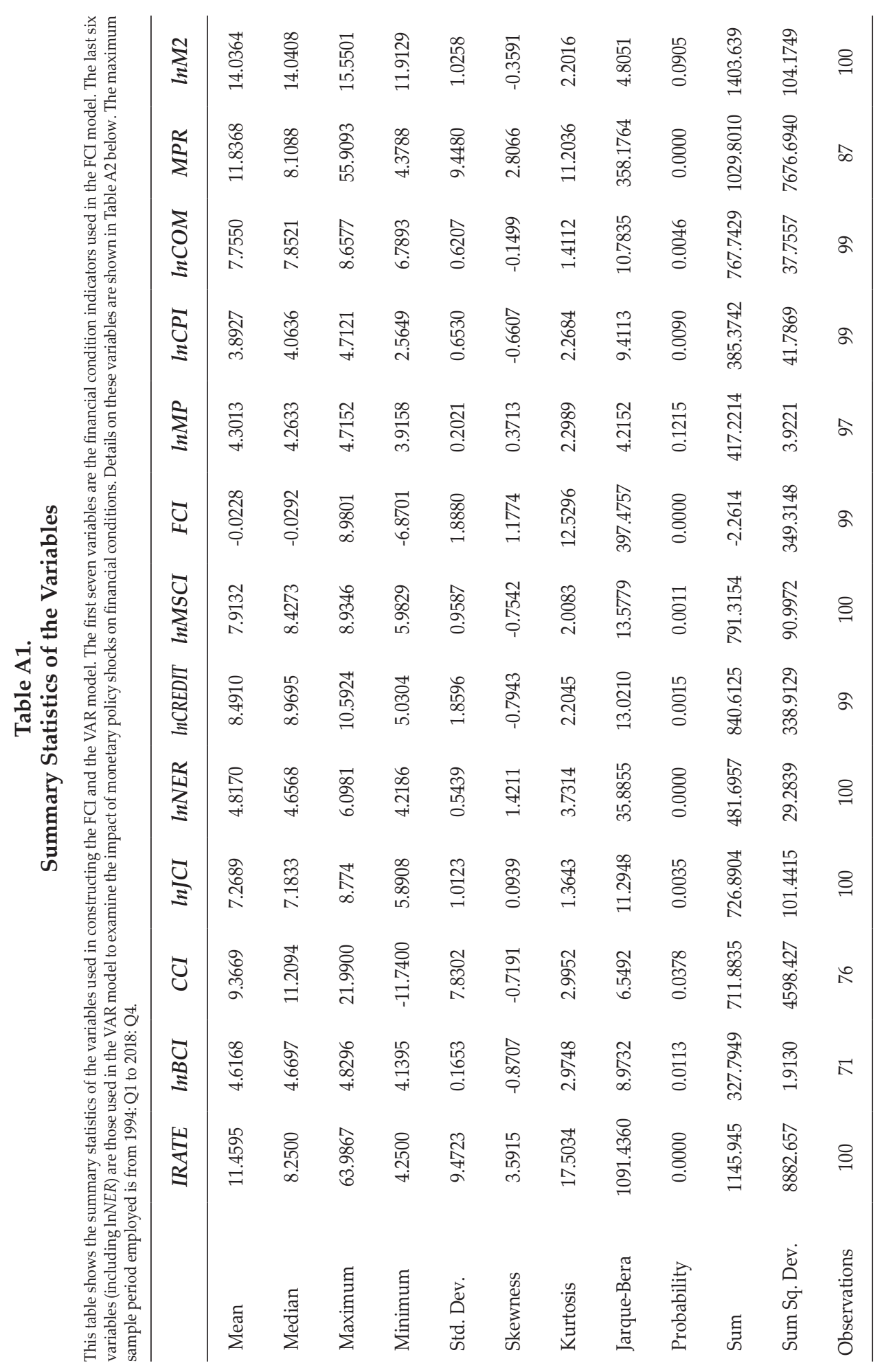




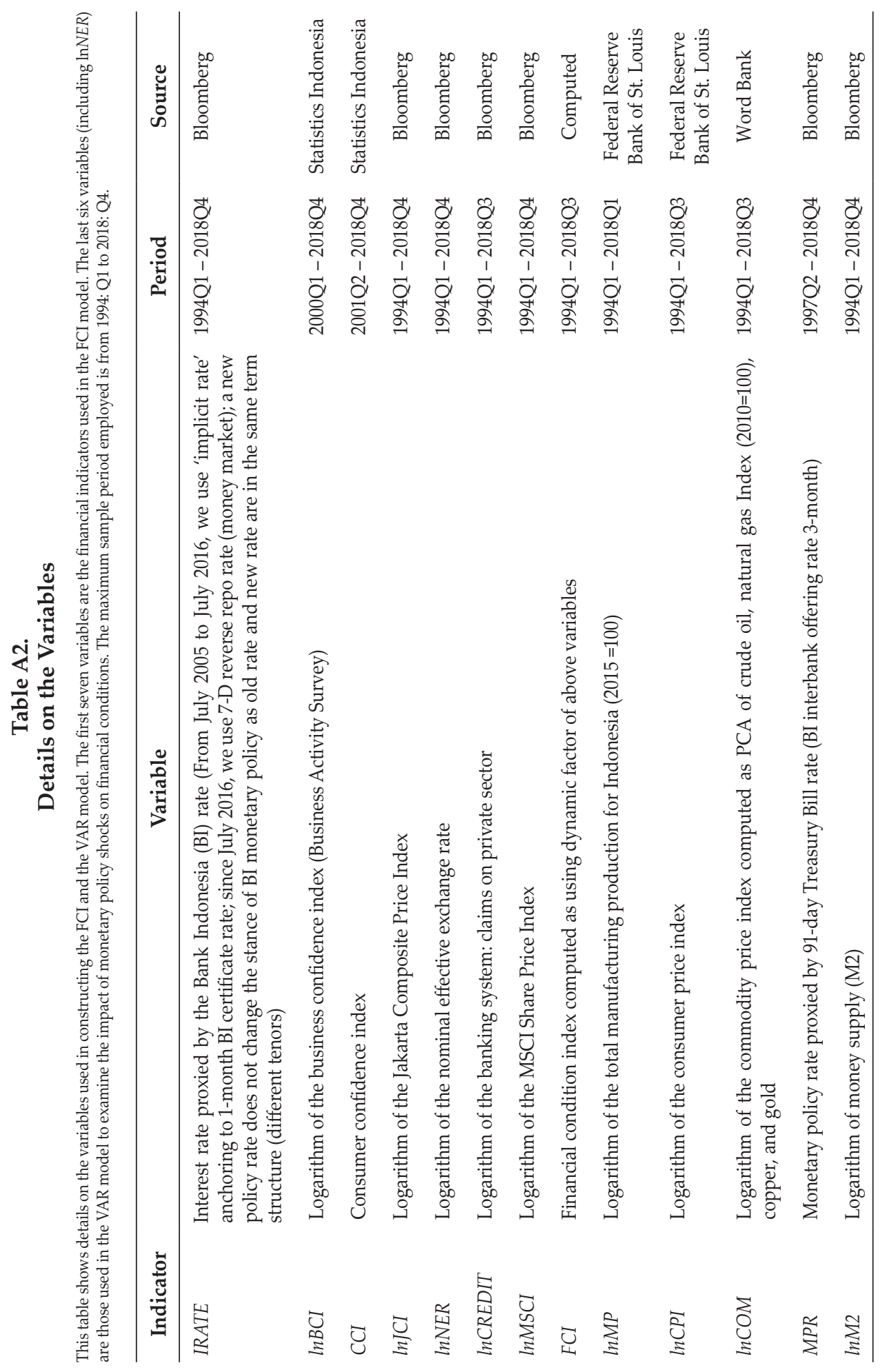

